MANFRON, Bruno Werner; CALETTI, Leandro. Bitcoin: uma análise sobre possibilidades de regulamentação. Revista Eletrônica Direito e Política, Programa de Pós-Graduação Stricto Sensu em Ciência Jurídica da UNIVALI, Itajaí, v.14, n.2, 20 quadrimestre de 2019. Disponível em: www.univali.br/direitoepolitica - ISSN 1980-7791

\title{
BITCOIN: UMA ANÁLISE SOBRE POSSIBILIDADES DE REGULAMENTAÇÃO
}

\author{
BITCOIN: AN ANALYSIS OF REGULATORY POSSIBILITIES
}

\author{
Bruno Werner Manfron' \\ Leandro Caletti ${ }^{2}$
}

\begin{abstract}
RESUMO
O presente trabalho tem como objetivo fazer uma análise inicial do fenômeno das criptomoedas, representadas, aqui, pelo Bitcoin, visto que é a pioneira e a que possui maior repercussão na comunidade jurídica atualmente. Analisa-se o tema a partir do desenvolvimento da globalização e da emergência de um Direito Global e Transnacional. Por fim, se discorre sobre duas possibilidades de regulamentação, quais sejam: (i) a criação de um tratado internacional, estabelecendo critérios às condutas dos usuários; (ii) a utilização de regras costumeiras, oriundas das relações entre os usuários, estabelecendo normas de conduta.
\end{abstract}

PALAVRAS-CHAVE: Criptomoedas; Bitcoin; Globalização; Direito Transnacional; Regulamentação.

\begin{abstract}
:
The present article has as objective to make a general analysis of the phenomenon of the cryptocurrencies, represented here by Bitcoin, since it is the pioneer and one that has greater repercussion in the legal community. The theme is analyzed based on the development of globalization and the emergence of a Global and Transnational Law. Finally, two regulatory possibilities are discussed, namely: (i) the creation of an international treaty, establishing criteria for the conduct of users; (ii) the use of consuetudinary law, derived from the relationships among users, establishing rules of conduct.
\end{abstract}

KEYWORDS: Cryptocurrencies; Bitcoin; Globalization; Transnational Law; Regulamentation.

1 Graduado da Faculdade de Direito, IMED - Passo Fundo. <bruno.manfron@gmail.com>

2 Mestre em Direito pela Faculdade Meridional/IMED (Bolsista PROSUP/CAPES). Professor da Escola de Direito (Graduação) da Faculdade Meridional/IMED. Professor do Programa de Pós-Graduação Lato Sensu em Direito da Faculdade Meridional/IMED. Membro dos Grupos de Pesquisas Transnacionalismo e Circulação de Modelos Jurídicos, Ética, Cidadania e Sustentabilidade e Direitos Culturais e Pluralismo Jurídico, vinculados ao Programa de Pós-Graduação Stricto Sensu em Direito da Faculdade Meridional/IMED. Advogado (OAB/RS). 
MANFRON, Bruno Werner; CALETTI, Leandro. Bitcoin: uma análise sobre possibilidades de regulamentação. Revista Eletrônica Direito e Política, Programa de Pós-Graduação Stricto Sensu em Ciência Jurídica da UNIVALI, Itajaí, v.14, n.2, $2^{\circ}$ quadrimestre de 2019. Disponível em: www.univali.br/direitoepolitica - ISSN 1980-7791

\section{INTRODUÇÃO}

A partir da eclosão do fenômeno da globalização, com a Revolução Tecnológica e a consequente condensação do tempo e do espaço, o mundo encontra-se conectado. Com isso, surgem novos fenômenos que desafiam a estrutura clássica do direito nacional. Para além de outros temas que poderiam ser analisados, como a questão ambiental ou do direito do trabalho diante de um mundo globalizado, será analisado, no presente trabalho, como o fenômeno das criptomoedas vai de encontro à estrutura clássica do direito nacional. Atualmente, o tema tem sido motivo de diversos debates (e embates) entre experts das áreas jurídicas e econômicas, principalmente no tangente à eventual possibilidade de regulamentação.

O artigo divide-se em quatro tópicos. No primeiro tópico realiza-se esclarecimentos acerca da globalização. No segundo tópico, analisa-se a emergência de um Direito Transnacional, oriundo de atores não estatais. O terceiro tópico é voltado a uma conceituação do que é e de como funciona o Bitcoin, moeda digital analisada no presente artigo. No quarto e último tópico, analisa-se as alternativas à regulamentação das moedas digitais, tratando inicialmente sobre a criação de um tratado internacional, e, posteriormente, defendendo a utilização de regras costumeiras para estabelecer normas de conduta.

Valer-se-á do método dedutivo ${ }^{3}$ para desenvolver uma cadeia de raciocínio descendente, partindo de uma análise geral e culminando em uma análise específica, chegando (ou não) a uma conclusão. Para a melhor elucidação da pesquisa jurídica proposta, observa-se que a pesquisa bibliográfica é o método que mais se adéqua, ensejando a consecução de fichamentos, a defrontação de ideias e o desenvolvimento de uma mentalidade crítica na resposta da problemática sugerida.

\footnotetext{
3 PASOLD, Cesar Luiz. Metodologia da pesquisa jurídica: teoria e prática. São Paulo. Conceito Editorial, 2011., p. 207.
} 
MANFRON, Bruno Werner; CALETTI, Leandro. Bitcoin: uma análise sobre possibilidades de regulamentação. Revista Eletrônica Direito e Política, Programa de Pós-Graduação Stricto Sensu em Ciência Jurídica da UNIVALI, Itajaí, v.14, n.2, 20 quadrimestre de 2019. Disponível em: www.univali.br/direitoepolitica - ISSN 1980-7791

A relevância do artigo se dá, em um primeiro momento, pela ausência de regulação abrangente do Bitcoin (e das criptomoedas em geral) e pelas consequências jurídicas do surgimento do fenômeno, que ainda se apresentam como novidade para a comunidade acadêmica. Ademais, tendo em vista a novidade do assunto, pretende o artigo servir de base para maiores aprofundamentos por parte da academia.

\section{GLOBALIZAÇÃo}

A "Globalização" tem origem incerta e não se sabe ao certo se ela remonta ao Império Romano, ou às expedições portuguesas e espanholas que partiam em busca do "novo mundo", ou ainda se tem origem avanço das trocas comerciais, no período do Renascimento Europeu.

Tão controverso quanto sua origem são as tentativas de definir o significado do termo "Globalização". Ulrich Beck ${ }^{4}$ afirma que:

Por sua vez, continua a causar polêmica a questão: quando
teve início a globalização econômica? Alguns remetem os
primórdios do "sistema capitalista mundial" ao século XVI
(Immanuel Wallerstein), ao início do colonialismo, outros ao
surgimento das companhias internacionais. Para outros a
globalização teve início com o término do câmbio fixo ou com
a queda do bloco do Leste Europeu...
Talvez encontremos aqui as razões que fazem do discurso e
do conceito da globalização algo tão inconstante. Buscar para
ele uma definição mais parece uma tentativa de pregar um
pudim na parede.

Apesar disso, busca o autor dar um sentido ao termo. Diferencia, assim, o conceito de "globalismo" e o conceito de "globalização" ou "globalidade". O primeiro diz respeito à dominação da economia, demandando que os Estados, enquanto sistema complexo, sejam ordenados como uma instituição privada. Sendo assim, para cumprir com suas metas as empresas impõe condições ${ }^{5}$.

\footnotetext{
${ }^{4}$ BECK, Ulrich. O que é globalização? Equívocos do Globalismo: respostas à Globalização. Tradução: André Carone. São Paulo: Paz e Terra, 1999., p. 46

${ }^{5}$ BECK, Ulrich. O que é globalização? Equívocos do Globalismo: respostas à Globalização., 1999, p. $27-28$
} 
MANFRON, Bruno Werner; CALETTI, Leandro. Bitcoin: uma análise sobre possibilidades de regulamentação. Revista Eletrônica Direito e Política, Programa de Pós-Graduação Stricto Sensu em Ciência Jurídica da UNIVALI, Itajaí, v.14, n.2, $2^{\circ}$ quadrimestre de 2019. Disponível em: www.univali.br/direitoepolitica - ISSN 1980-7791

De outra banda, leciona que o termo "globalidade" faz alusão a uma sociedade mundial plural, na qual não existem mais espaços delimitados, porém sem unidade.

Globalidade denomina o fato de que, daqui para a frente, nada que venha a acontecer em nosso planeta será um fenômeno espacialmente delimitado, mas o inverso: que todas as descobertas, triunfos e catástrofes afetam a todo o planeta, e que devemos redirecionar e reorganizar nossas vidas e nossas ações em torno do eixo 'global-local'. ${ }^{6}$

A partir desses conceitos, busca o autor elucidar a globalização como um processo de desnacionalização dos Estados nacionais, transformando-se em transnacionais, a partir das interferências de atores externos, ou internacionais, especialmente relacionado a suas diretrizes políticas, de soberania, de identidade e de suas redes de comunicações. Ademais, defende que se origina um capitalismo global não hegemônico, desorganizado e sem um regime internacional político e/ou econômico.

Certo é que, apesar de não haver um consenso sobre sua origem ou sua definição, o termo "Globalização" causou furor na literatura sociológica, política e jornalística, resultando no que se denomina de "the great globalization debate". Esse grande debate tomou tamanhas proporções que a United Nations Development Programme (UNDP), lançou o Human Development Report do ano de 1999, com discussões sobre diversos aspectos da globalização.

O foco central do globalization debate é o aspecto econômico-financeiro da globalização. Evidencia-se uma revolução econômica oriunda especialmente do desenvolvimento tecnológico, dando origem a uma transformação global. Resultou-se, assim, em uma economia global, aberta, integrada e interdependente, tendo como requisito crucial o fluxo irrestrito de matériasprimas, manufaturados, fontes energéticas, capitais, força de trabalho e conhecimentos técnico-científicos ${ }^{7}$.

${ }^{6}$ BECK, Ulrich. O que é globalização? Equívocos do Globalismo: respostas à Globalização., 1999, p.31.

7 ZOLO, Danilo. Globalização: Um mapa dos problemas. Florianópolis: Conceito Editorial, 2010., p. 33. 
MANFRON, Bruno Werner; CALETTI, Leandro. Bitcoin: uma análise sobre possibilidades de regulamentação. Revista Eletrônica Direito e Política, Programa de Pós-Graduação Stricto Sensu em Ciência Jurídica da UNIVALI, Itajaí, v.14, n.2, 20 quadrimestre de 2019. Disponível em: www.univali.br/direitoepolitica - ISSN 1980-7791

Diante desse cenário, foi necessária uma supressão de obstáculos que dificultariam à dinâmica do mercado global, incluindo-se as fronteiras dos Estados nacionais, propiciando, dessa forma, a ampliação dos investimentos no exterior e a viabilidade de aproveitar das vantagens de cada economia local.

Por conseguinte, ocasionou-se uma alteração na velocidade e no modo como se dá a circulação de dinheiro.

A deregulation financeira, por um lado, imprimiu uma excepcional aceleração à circulação do dinheiro; por outro lado, permitiu que milhares de operadores, em larguíssima parte pertencentes às áreas mais ricas do planeta, realizem substanciais lucros servindo-se do mercado eletrônico de capitals, que não possui nenhuma relação direta com a troca de produtos e de serviços reais ${ }^{8}$.

A globalização ganhou força principalmente a partir da ocorrência de algumas revoluções. A primeira delas foi a revolução tecnológica, intensificada a partir do século XX, contando com grande contribuição das duas grandes guerras mundiais e possibilitou o surgimento de novos materiais (como a fibra ótica), o descobrimento de novas fontes energéticas (como por exemplo a energia eólica, a solar, a extração de petróleo em águas profundas), o desenvolvimento da nanotecnologia e da Física Quântica, a invenção de computadores, da internet, de telefones celulares, softwares, dentre outros.

Ademais, interessa fazer alusão à revolução da tecnologia da informação. Esta diz respeito a um conjunto de inovações no que tange à microeletrônica, à informática, à optoeletrônica e à engenharia genética. Tais novidades possibilitaram a compressão do tempo e do espaço e proporcionaram uma conexão da sociedade, a qual foi cunhada de "sociedade em rede".

A intitulada sociedade em rede é, da mesma forma, uma sociedade da informação, na qual tudo está interligado. Há, portanto, uma mudança no capitalismo industrial, exigindo-se para esse uma reorientação a fim de se adaptar aos

\footnotetext{
8 ZOLO, Danilo. Globalização: Um mapa dos problemas., 2010, p. 44.

9 CASTELLS, Manuel. La era de la información: economía, sociedad y cultura. La sociedad red. Versión castellana de Carmen Martínez Gimeno y Jesús Alborés. $2^{a}$ ed. Vol. 1. Madrid: Alianza Editorial, 2000., p. 56-57.
} 
MANFRON, Bruno Werner; CALETTI, Leandro. Bitcoin: uma análise sobre possibilidades de regulamentação. Revista Eletrônica Direito e Política, Programa de Pós-Graduação Stricto Sensu em Ciência Jurídica da UNIVALI, Itajaí, v.14, n.2, $2^{\circ}$ quadrimestre de 2019. Disponível em: www.univali.br/direitoepolitica - ISSN 1980-7791

contornos da globalização. Surgem, para tanto, corporações bilionárias que passam a explorar a "era da informação", eliminando barreiras e interligando pessoas ao redor do globo, por meio da comunicação. Google, Yahoo, Facebook, Twitter, Instagram, Whatsapp, dentre outros, já figuram como algumas das maiores empresas do mundo, tendo seu valor de mercado comparável ao PIB de alguns dos países mais ricos ${ }^{10}$.

Possibilitou-se, assim, o advento de novas tecnologias que fazem frente à soberania dos Estados nacionais, assim como fazem frente à predominância de instituições financeiras globais, como, por exemplo, a criação do Bitcoin. ${ }^{11}$

\section{BREVES COMENTÁRIOS SOBRE O DIREITO TRANSNACIONAL}

O advento do "Estado moderno" e soberano se deu concomitantemente com o surgimento do Direito Internacional, remontando ao ano de 1648 , quando se deu a assinatura de diversos tratados, intitulados de "Paz de Westphalia", pondo fim a Guerra dos Trinta Anos. Surge, então, a "doutrina da soberania"12, para a qual a soberania estatal passa a ser expressa, interna ou externamente, com plena independência internacional. Além disso, origina-se, também, a partir da "Paz de Westphalia", um novo sistema internacional, com o reconhecimento do princípio da igualdade formal dos Estados. Constata-se o princípio de uma pequena agremiação internacional, que estabelece alguns objetivos comuns, como a paz e a segurança duradoura.

De fato, antes dos tratados de Westfália não existia uma sociedade internacional com poder político para sujeitar os Estados ao cumprimento de suas regras de conduta. Portanto a Paz de Westfália pode ser considerada como um verdadeiro "divisor de águas" na história do Direito Internacional Público, momento em que se desprenderam as regras fundamentais que passaram a presidir as relações entre os Estados

10 GALINDO, Cristina. Quando as empresas são mais poderosas que os países. El País. São Paulo, 08 de novembro de $2017 . \quad$ Disponível em: https://brasil.elpais.com/brasil/2017/11/03/economia/1509714366_037336.html.

$11 \mathrm{O}$ tema das Bitcoin (como representante das criptomoedas) será tema da segunda parte do artigo.

12 MAZZUOLI, Valerio de Oliveira. Curso de Direito Internacional Público. 5. ed. São Paulo: Revista dos Tribunais, 2011., p. 55. 
MANFRON, Bruno Werner; CALETTI, Leandro. Bitcoin: uma análise sobre possibilidades de regulamentação. Revista Eletrônica Direito e Política, Programa de Pós-Graduação Stricto Sensu em Ciência Jurídica da UNIVALI, Itajaí, v.14, n.2, 20 quadrimestre de 2019. Disponível em: www.univali.br/direitoepolitica - ISSN 1980-7791

europeus, reconhecendo ao princípio de igualdade absoluta dos Estados o caráter de regra internacional fundamental.

Além disso, esse fato histórico teve grande importância internacional por marcar o surgimento do que hoje conhecemos por Estado moderno, que a partir desse momento passou a se tornar o sujeito mais importante do Direito Internacional (é certo que com os temperamentos introduzidos pelas normas mais modernas de limitação da autoridade absoluta dos monarcas). ${ }^{13}$

Esse "sistema" estabilizou-se, em especial na Europa, nos séculos XVIII e XIX, tornando-se universal nas primeiras décadas do século XX. Permaneceu substancialmente invariável até a Segunda Guerra Mundial, e somente foi revisto, brevemente, com a assinatura da Carta das Nações Unidas, em 26 de junho de 1945. Apesar de reforçar a soberania dos Estados ${ }^{14}$, foi instituído o Conselho de Segurança ${ }^{15}$, com poderes supranacionais ${ }^{16}$.

Somente depois da Segunda Guerra Mundial e em razão das brutalidades ocorridas no período e também de suas consequências negativas, nota-se a necessidade de proteção contra o poder de destruição das guerras, dando origem a uma reforma no ramo do direito internacional público. Os Estados soberanos aderem, então, ao cronograma da ONU e de outras organizações internacionais, comprometendo-se com os objetivos fixados pela política jurídica internacionalista. Promove-se, a partir disso, o reconhecimento do princípio da autodeterminação dos povos, dando início a uma descolonização e, por conseguinte, a cena internacional passa a conter inúmeros novos Estados antes inexistentes. Contudo, tal situação desencadeou em novos conflitos, não se coadunando com os objetivos inicialmente estabelecidos ${ }^{17}$.

Pouco a pouco, em especial por causa das novas tecnologias desenvolvidas nos campos da informação e comunicação que, como já referido, possibilitou o

13 MAZZUOLI, Valerio de Oliveira. Curso de Direito Internacional Público. 5. ed., 2011.

${ }^{14}$ Artigo 2. A Organização e seus membros, para a realização dos propósitos mencionados no artigo 1, agirão de acordo com os seguintes Princípios: 1. A Organização é baseada no princípio da igualdade soberana de todos os seus membros.

15 O Conselho de Segurança da Onu foi estabelecido nos artigos 23 à 32 da Carta.

16 ZOLO, Danilo. Globalização: Um mapa dos problemas., 2010, p. 57.

${ }^{17}$ GUIMARÃES, Isaac Sabbá. Globalização, transnacionalidade e um novo marco conceitual de soberania política e a necessidade de adequações jurídico-políticas da UNASUL. Universitas Jus, Brasília, v. 24, n. 3, p.109-122, nov. 2013, p.109-122. 
MANFRON, Bruno Werner; CALETTI, Leandro. Bitcoin: uma análise sobre possibilidades de regulamentação. Revista Eletrônica Direito e Política, Programa de Pós-Graduação Stricto Sensu em Ciência Jurídica da UNIVALI, Itajaí, v.14, n.2, 20 quadrimestre de 2019. Disponível em: www.univali.br/direitoepolitica - ISSN 1980-7791

surgimento de empresas que lucram com a chamada "era da informação", empresas estas que se encontram, atualmente, com valor de mercado comparável a Estados nações ricos, passou-se a notar uma influência cada vez mais constante de atores não estatais na sociedade internacional. Nota-se, assim, um processo progressivo de perda de prerrogativas do princípio da soberania ${ }^{18}$, transferindo-se prerrogativas do poder soberano e, por consequência, a possibilidade de ocupação de posições centrais no âmbito normativo, tendo como exemplos evidentes disso - estabelecimento da Organização Mundial do Comércio, da Organização Internacional do Trabalho, da Corte Internacional Arbitral, dentre outros. Tratase, portanto, de esferas transnacionais de regulação normativa ou, até mesmo, de jurisdição ${ }^{19}$.

Exemplo mais evidente desse direito além do Estado é a Lex mercatoria, a qual se baseia "nas práticas comerciais usais no mundo inteiro, nas diretivas unitárias, nos contratos padronizados, nas atividades de associações econômicas globias, em códigos de conduta e nas decisões das cortes arbitrais internacionais"20.

A primeira manifestação do Direito Transnacional ${ }^{21}$ se dá com Philip Jessup, na década de 1950, conceito que englobaria "o conjunto de normas (nacionais, internacionais e de outras fontes, especialmente de atores privados) que regula ações ou )acontecimentos que transcendem as fronteiras nacionais"22.

18 TEIXEIRA, Anderson Vichinkeski. Direito público transnacional: por uma compreensão sistêmica das esferas transnacionais de regulação jurídica. Novos Estudos Jurídicos, [s.l.], v. 19, n. 2, p.400-429, 31 jul. 2014. Editora UNIVALI. http://dx.doi.org/10.14210/nej.v19n2.p400-429., p. 407.

19 STAFFEN, Marcio Ricardo. Superlegality, global law and the transnational corruption combat.

Revista Brasileira de Direito, Passo Fundo, v. 14, n. 1, p. 111-130, abr. 2018.

20 TEUBNER, Gunther. A Bukowina global sobre a emergência de um pluralismo jurídico transnacional. Impulso (piracicaba), (s.l.), v. 14, n. 33, p.9-31, set. 2003., p. 15-16.

21 No presente artigo, tratar-se-á Direito Transnacional e Global como sinônimos. Para maiores detalhes recomenda-se: STAFFEN, Márcio Ricardo. Interfaces do direito global. 2. Ed. Rio de Janeiro: Lumen Juris, 2018.

22 RAMOS, André de Carvalho. Direito internacional privado e o direito transnacional: entre a unificação e a anarquia. Revista de Direito Internacional, [s.I.], v. 13, n. 2, p.504-521, 6 nov. 2016. Centro de Ensino Unificado de Brasilia. http://dx.doi.org/10.5102/rdi.v13i2.4169., p. 506507. 
MANFRON, Bruno Werner; CALETTI, Leandro. Bitcoin: uma análise sobre possibilidades de regulamentação. Revista Eletrônica Direito e Política, Programa de Pós-Graduação Stricto Sensu em Ciência Jurídica da UNIVALI, Itajaí, v.14, n.2, 20 quadrimestre de 2019. Disponível em: www.univali.br/direitoepolitica - ISSN 1980-7791

Ademais, verifica-se assim a globalização do direito não a partir de entes estatais, mas sim originados em um processo fragmentado de globalização, orientado por sistemas parciais individuais da sociedade e em velocidades distintas:

O que podemos observar hoje em dia, em matéria de globalização, não é a sociedade mundial paulatinamente configurada pela política internacional, mas um processo extremamente contraditório, integralmente fragmentado de globalização impulsionado pelos sistemas parciais individuais da sociedade em velocidades distintas. Em tais processos, a política não apenas perdeu o seu papel de liderança, mas regrediu nitidamente em comparação com outras áreas parciais da sociedade. $\mathrm{Em}$ que pesem toda a internacionalidade da política e todo o direito internacional, a ênfase da política e do direito ainda nos dias de hoje recai no Estado-nação. E mais: fazem-se sentir tendências nítidas, até dramáticas, a uma maior regionalização e localização da política. Na via da globalização, a política foi claramente ultrapassada pelos outros sistemas sociais. Já há muito tempo ela está a caminho das suas global villages respectivamente próprias. E essas global villages se preparam para defender tenazmente a sua autonomia diante das pretensões hegemônicas da política. Isso vale, em grau especial, para a globalização do direito. ${ }^{23}$

Tal fato se evidencia sobremaneira em relação ao Bitcoin ${ }^{24}$, especialmente devido ao seu caráter revolucionário e também por se tratar de um fenômeno de extrema complexidade, que produz impacto significativo na seara jurídica, de modo que o Direito ainda resta inerte sobre a possibilidade de uma eventual regulamentação.

\section{O QUE É E COMO FUNCIONA O BITCOIN}

Necessário ressaltar que, no presente artigo, será analisada uma das diversas moedas digitais existentes, qual seja, o Bitcoin. A escolha se deu em razão de esta ser a pioneira, e a qual gera maior repercussão no mundo jurídico.

\footnotetext{
23 TEUBNER, Gunther. A Bukowina global sobre a emergência de um pluralismo jurídico transnacional., 2003, p. 12.

${ }^{24}$ No presente artigo será tratado especialmente do Bitcoin, não desconsiderando as demais criptomoedas, mas sim por se tratar do marco inicial do fenômeno, que repercute despertando o interesse da comunidade jurídica.
} 
MANFRON, Bruno Werner; CALETTI, Leandro. Bitcoin: uma análise sobre possibilidades de regulamentação. Revista Eletrônica Direito e Política, Programa de Pós-Graduação Stricto Sensu em Ciência Jurídica da UNIVALI, Itajaí, v.14, n.2, 20 quadrimestre de 2019. Disponível em: www.univali.br/direitoepolitica - ISSN 1980-7791

O Bitcoin tem origem em 2008, quando Satoshi Nakamoto 25 lança um paper intitulado "Bitcoin: a Peer-to-Peer Electronic Cash System"26. Caracteriza-se o Bitcoin por ser uma moeda digital peer-to-peer (ou ponto a ponto), totalmente descentralizada. A moeda funciona de forma que suas transações são verificadas através do uso de criptografia de chave pública, de modo que cada indivíduo possui duas chaves: uma pública, compartilhada com todos; e uma chave privada, mantida em segredo. A transação é registrada, atribuída data e hora e exibida em um bloco da blockchain (livro-razão da rede Bitcoin). "A criptografia de chave pública garante que todos os computadores na rede tenham um registro constantemente atualizado e verificado de todas as transações dentro da rede Bitcoin, o que impede gasto duplo e qualquer tipo de fraude ${ }^{127}$.

Portanto, trata-se de uma consequência da revolução tecnológica-informática, visto que combina duas tecnologias: "a distribuição de um banco de dados por meio de uma rede peer-to-peer e a criptografia"'28.

Pode parecer ironia, porém, o fato de o Bitcoin ter surgido em meio a uma das maiores crises da história ${ }^{29}$ revela o seu caráter revolucionário. O monopólio dos bancos centrais, seja na emissão de moeda ou na organização e controle do sistema bancário, mostrou claros sinais de arbitrariedade. Ademais, há a gradativa perda de privacidade financeira.

Os motivos fundamentais que impulsionaram a criação do Bitcoin são, portanto, evidentes: um sistema financeiro instável e com elevado nível de intervenção estatal e a crescente perda de privacidade financeira. Mas esse estado de coisas não é novidade. A intervenção dos governos no âmbito monetário é milenar, assim como a cumplicidade e conivência do sistema bancário. A diferença entre o sistema financeiro mundial atual e o de cem anos atrás é meramente de grau; na sua essência, a intervenção estatal prevalece tanto hoje

${ }^{25}$ Trata-se de um pseudônimo. Até os dias atuais não se sabe a real identidade de Satoshi Nakamoto, se é um individuo apenas ou um grupo de experts em informática que lançaram esse paper.

26 NAKAMOTO, Satoshi. Bitcoin: A Peer-to-Peer Electronic Cash System. 2008. Disponível em: \&lt; https://bitcoin.org/bitcoin.pdf\&gt; . Acesso em: 16/07/2018

27 ULRICH, Fernando. Bitcoin: a moeda na era digital. São Paulo: Instituto Ludwig von Mises Brasil, 2014., p. 18-19.

28 ULRICH, Fernando. Bitcoin: a moeda na era digital, 2014, p.19.

${ }^{29} \mathrm{~A}$ crise do sub-prime, que tem como marco a quebra do banco Lehman Brothers, em setembro de 2008. 
MANFRON, Bruno Werner; CALETTI, Leandro. Bitcoin: uma análise sobre possibilidades de regulamentação. Revista Eletrônica Direito e Política, Programa de Pós-Graduação Stricto Sensu em Ciência Jurídica da UNIVALI, Itajaí, v.14, n.2, 20 quadrimestre de 2019. Disponível em: www.univali.br/direitoepolitica - ISSN 1980-7791

\begin{abstract}
como no início do século $\mathrm{XX}$. Por que então algo como o Bitcoin não surgiu antes? Por que precisamos assistir ao sistema financeiro mundial tornar-se tão vulnerável, a ponto de quase testemunharmos o seu mais absoluto colapso em 2008? Simplesmente porque, antes, uma tecnologia como a internet não estava disponível e madura como hoje está; de fato, a rede mundial de computadores foi o que viabilizou a criação do Bitcoin. A era da informação revolucionou diversos aspectos da cooperação social, e não poderia ser diferente com uma das instituições mais importantes para o convívio em sociedade, o dinheiro. ${ }^{30}$
\end{abstract}

Em suma, o Bitcoin (e as criptomoedas) é uma moeda virtual, totalmente descentralizadas, que utilizam de criptografia forte e surgem como alternativa às instituições financeiras tradicionais, em especial, para "intermediar a realização de negócios jurídicos no ciberespaço, agindo de forma substitutiva à moeda física e afastando a necessidade de intermediários fiduciários, que oneram as transações e o risco de falsificação, fraudes e depreciação da moeda"'31.

\title{
4 ALternativas PARA A REgUlamentaÇÃo DO BITCOIN (E DAS CRIPTOMOEDAS)
}

Dificilmente um fenômeno de tamanha repercussão mundial, que se consolida como um modo mais eficiente e econômico de realizar transações financeiras internacionais, passe despercebido às atenções dos Estados soberanos. Analisarse-á, assim, duas possibilidades de regulamentação, frente ao que vem sendo escrito pela comunidade jurídica.

\subsection{Elaboração de um tratado internacional}

Inicialmente, antes de adentrar no cerne da questão, merece breves comentários acerca do ciberespaço. Isto por que, é somente nele que o Bitcoin (e as criptomoedas em geral) pode se desenvolver plenamente, pois não pode estar sob

30 ULRICH, Fernando. Bitcoin: a moeda na era digital, 2014, p.39

31 ULRICH, Fernando. Bitcoin: a moeda na era digital, 2014, p. 19 
MANFRON, Bruno Werner; CALETTI, Leandro. Bitcoin: uma análise sobre possibilidades de regulamentação. Revista Eletrônica Direito e Política, Programa de Pós-Graduação Stricto Sensu em Ciência Jurídica da UNIVALI, Itajaí, v.14, n.2, 20 quadrimestre de 2019. Disponível em: www.univali.br/direitoepolitica - ISSN 1980-7791

a mercê de um Estado que possui o monopólio normativo, em que a emissão de moeda é matéria exclusiva da União ${ }^{32}$.

Assim, ciberespaço é um território múltiplo, sem identidade, constituído de todas as ferramentas de acesso à internet. Não há uma delimitação física, tampouco pertence a uma nação, sem a prevalência de individualidades culturais, leis, tempo ou espaço ${ }^{33}$.

Não há, portanto, como se falar em uma imposição de um processo legislativo estatal frente a um fenômeno que está essencialmente ligado ao ciberespaço. Uma regulamentação por um processo legislativo tradicional, para regulamentação dentro de um território delimitado de um Estado nação não é possível.

Vislumbra-se, entretanto, a possibilidade de elaboração de um tratado internacional ${ }^{34}$, no qual, a partir da conjugação de vontades de estados soberanos e de Organizações Internacionais, seriam estabelecidos critérios à conduta dos usuários das criptomoedas ${ }^{35}$.

Contudo, no tocante à elaboração de um tratado internacional surge um problema: é possível que um Estado não reconheça os termos do tratado, negando-se a assiná-lo. Assim, todos os negócios jurídicos celebrados dentro daquele território geográfico seriam contrários ao direito interno.

\footnotetext{
32 SOUZA, Ranidson Gleyck Amâncio. Território das criptomoedas: limites à regulamentação estatal quanto à circulação de moedas no ciberespaço e possíveis alternativas. Revista Brasileira de Políticas Públicas, [s.I.], v. 7, n. 3, p.61-78, 6 fev. 2018. Centro de Ensino Unificado de Brasilia. http://dx.doi.org/10.5102/rbpp.v7i3.4902., p. 69.

33 SOUZA, Ranidson Gleyck Amâncio. Território das criptomoedas: limites à regulamentação estatal quanto à circulação de moedas no ciberespaço e possíveis alternativas. Revista Brasileira de Políticas Públicas, 2018, p. 69-73.

${ }^{34}$ Mazzuoli refere-se aos tratados como uma fonte do direito internacional. Como se vê: "Os tratados internacionais são, incontestavelmente, a principal e mais concreta fonte do Direito Internacional Público na atualidade, não apenas em relação à segurança e estabilidade que trazem nas relações internacionais, mas também porque tornam o direito das gentes mais representativo e autêntico, na medida em que se consubstanciam na vontade livre e conjugada dos Estados e das Organizações Internacionais, sem a qual não subsistiriam". MAZZUOLI, Valerio de Oliveira. Curso de Direito Internacional Público., 2011, p. 114.

35 SOUZA, Ranidson Gleyck Amâncio. Território das criptomoedas: limites à regulamentação estatal quanto à circulação de moedas no ciberespaço e possíveis alternativas. Revista Brasileira de Políticas Públicas, 2018, p. 73.
} 
MANFRON, Bruno Werner; CALETTI, Leandro. Bitcoin: uma análise sobre possibilidades de regulamentação. Revista Eletrônica Direito e Política, Programa de Pós-Graduação Stricto Sensu em Ciência Jurídica da UNIVALI, Itajaí, v.14, n.2, 20 quadrimestre de 2019. Disponível em: www.univali.br/direitoepolitica - ISSN 1980-7791

\subsection{Autorregulação regulada nos moldes da Lex Mercatoria}

Ante o problema acima exposto, apresenta-se a segunda alternativa à regulação do Bitcoin, que consiste na utilização de regras constumeiras, a exemplo da Lex Mercatoria.

A Lex Mercatoria, surge na Idade Média, a partir de estatutos das corporações, costumes mercantis e decisões das jurisdições mercantis ${ }^{36}$ a fim de proporcionar segurança jurídica nas relações mercantis, diante da ausência de um poder central controlador. Com o passar do tempo e o desenvolvimento de novas práticas mercantis, assim como de novas tecnologias, reformulou-se os preceitos da "antiga" Lex Mercatoria, elaborando-se a "nova" Lex Mercatoria37, que consiste "no conjunto de regras e instâncias de solução de controvérsias produzidas e geridas, em geral, por entes privados" ${ }^{\prime 38}$.

Assim, diante da impossibilidade de se criarem leis internas para regulamentação dos Bitcoins e das criptomoedas, assim como da dificuldade de vigência global de um tratado internacional sobre o tema, aparenta-se que as regras costumeiras, oriunda dos costumes das relações entre os usuários, possam ser o mecanismo mais eficiente de "regulamentação" do fenômeno. Também por que suas características essenciais são coerentes com o cenário do ciberespaço, sendo descentralizadas e disruptivas ${ }^{39}$.

Portanto, dadas as características essenciais das criptomoedas e da blockchain, não se vislumbra a possibilidade de uma regulamentação a partir do direito interno puro, assim como pelo direito internacional público. Assim, defende-se a adoção

\footnotetext{
36 RAMOS, André de Carvalho. Direito internacional privado e o direito transnacional: entre a unificação e a anarquia. Revista de Direito Internacional, 2016, p. 503.

37"A nova lex mercatoria retoma o desejo de afastar o Estado (e suas políticas públicas de intervenção) das relações privadas, privilegiando os atores econômicos que podem influenciar tanto a edição das regras quanto das decisões arbitrais." RAMOS, André de Carvalho. Direito internacional privado e o direito transnacional: entre a unificação e a anarquia. Revista de Direito Internacional, p. 509.

38 RAMOS, André de Carvalho. Direito internacional privado e o direito transnacional: entre a unificação e a anarquia. Revista de Direito Internacional, 2016, p. 509.

39 SOUZA, Ranidson Gleyck Amâncio. Território das criptomoedas: limites à regulamentação estatal quanto à circulação de moedas no ciberespaço e possíveis alternativas. Revista Brasileira de Políticas Públicas, 2018, p. 75.
} 
MANFRON, Bruno Werner; CALETTI, Leandro. Bitcoin: uma análise sobre possibilidades de regulamentação. Revista Eletrônica Direito e Política, Programa de Pós-Graduação Stricto Sensu em Ciência Jurídica da UNIVALI, Itajaí, v.14, n.2, 20 quadrimestre de 2019. Disponível em: www.univali.br/direitoepolitica - ISSN 1980-7791

alternativa da autorregulação regulada, expedientes de soft law, instituídos a partir de uma governança global.

O termo governança global pode ser analisado sobre diversos ângulos, dado o alargamento do conceito pelas ciências sociais com o passar do tempo. Sumariamente, ele passou a significar todas as formas de produção de ordem social, tais como mercados, estados e redes.

Vale destacar que "governança" não é, e nem pode ser, sinônimo de "governo". Enquanto o termo "governo" conecta-se a atividades vinculadas ao Estado, governança refere-se às atividades baseadas em poderes oriundos não somente de políticas públicas, dirigidas a objetivos comuns e derivada de responsabilidades que podem estar previstas em lei ou não ${ }^{40}$.

De todo modo, de acordo com a alternativa proposta, valer-se-á de mecanismos de autorregulação regulada, a partir de uma governança global, para "legislar", ainda que não a partir de um processo legislativo tradicional, oriundo de um Estado nação, estabelecendo-se conceitos, normas de conduta, métodos de resolução de conflitos. A eficácia de tal normatividade dar-se-á pela facticidade, ou seja, pela práxis.

Portanto, dadas as características essenciais das criptomoedas e da blockchain, não se vislumbra a possibilidade de uma regulamentação a partir do direito interno puro, assim como pelo direito internacional público. Assim, defende-se a adoção alternativa da autorregulação regulada, expedientes de soft law, instituídos a partir de uma governança global.

\section{CONSIDERAÇÕES FINAIS}

Não restam dúvidas quanto aos impactos causados pelo Bitcoin na esfera jurídica, em especial por que se trata de uma novidade que o Direito invariavelmente vai

\footnotetext{
40 VOLPON, Fernanda; RIBEIRO, Marilda Rosado de Sá. Desafios da governança energética global e a participação do BRICS na construção de um novo paradigma energético. Revista de Direito Internacional, [s.I.], v. 15, n. 1, p.199-220, 27 abr. 2018. Centro de Ensino Unificado de Brasilia. http://dx.doi.org/10.5102/rdi.v15i1.5090., p. 208.
} 
MANFRON, Bruno Werner; CALETTI, Leandro. Bitcoin: uma análise sobre possibilidades de regulamentação. Revista Eletrônica Direito e Política, Programa de Pós-Graduação Stricto Sensu em Ciência Jurídica da UNIVALI, Itajaí, v.14, n.2, 20 quadrimestre de 2019. Disponível em: www.univali.br/direitoepolitica - ISSN 1980-7791

ter que enfrentar nos próximos tempos. Elegeram-se, no presente artigo, duas hipóteses sobre a possibilidade (ou não) de uma regulamentação. Não se pretendeu esgotar todas as possibilidades, mas sim fazer referência a um panorama geral.

Em um primeiro momento, elenca-se a possibilidade de criação de um tratado internacional, a fim de estabelecer critérios para os usuários da moeda virtual Bitcoin. Porém, evidencia-se o problema da vigência global: pode ser que nem todos os Estados reconheçam e assinem o referido tratado. Então, surge como alternativa, nos moldes da Lex Mercatoria, o uso de regras costumeiras, que se originam nas relações entre os usuários, para estabelecer critérios de conduta, formando uma grande rede de governança global, firmando-se expedientes de soft law que regeriam a matéria.

Aparentemente, a segunda opção, diante das dificuldades enfrentadas para uma regulamentação a partir de um tratado internacional, é a mais viável a ser aplicada ao Bitcoin (e as criptomoedas).

Ficam, portanto, essas breves considerações sobre o tema, sem o intento de esgotar seu conteúdo, uma vez que o principal objetivo do tema era chamar a atenção da academia para maiores discussões. No momento, não é possível fazer qualquer previsão certeira sobre qual caminho será eleito para tratar sobre uma eventual regulamentação dos Bitcoins, visto que além de um fenômeno recente que necessita de maiores tratativas por parte dos juristas.

\section{REFERENCIAS BIBLIOGRÁFICAS}

BECK, Ulrich. O que é globalização? Equívocos do Globalismo: respostas à Globalização. Tradução: André Carone. São Paulo: Paz e Terra, 1999.

CASTELLS, Manuel. La era de la información: economía, sociedad y cultura. La sociedad red. Versión castellana de Carmen Martínez Gimeno y Jesús Alborés. $2^{a}$ ed. Vol. 1. Madrid: Alianza Editorial, 2000.

GALINDO, Cristina. Quando as empresas são mais poderosas que os países. El País. São Paulo, 08 de novembro de 2017. Disponível em: https://brasil.elpais.com/brasil/2017/11/03/economia/1509714366_037336.html 
MANFRON, Bruno Werner; CALETTI, Leandro. Bitcoin: uma análise sobre possibilidades de regulamentação. Revista Eletrônica Direito e Política, Programa de Pós-Graduação Stricto Sensu em Ciência Jurídica da UNIVALI, Itajaí, v.14, n.2, $2^{\circ}$ quadrimestre de 2019. Disponível em: www.univali.br/direitoepolitica - ISSN 1980-7791

GUIMARÃES, Isaac Sabbá. Globalização, transnacionalidade e um novo marco conceitual de soberania política e a necessidade de adequações jurídico-políticas da UNASUL. Universitas Jus, Brasília, v. 24, n. 3, p.109-122, nov. 2013.

MAZZUOLI, Valerio de Oliveira. Curso de Direito Internacional Público. 5. ed. São Paulo: Revista dos Tribunais, 2011.

NAKAMOTO, Satoshi. Bitcoin: A Peer-to-Peer Electronic Cash System. 2008. Disponível em: < https://bitcoin.org/bitcoin.pdf>. Acesso em: 16/07/2018

PASOLD, Cesar Luiz. Metodologia da pesquisa jurídica: teoria e prática. São Paulo. Conceito Editorial, 2011.

RAMOS, André de Carvalho. Direito internacional privado e o direito transnacional: entre a unificação e a anarquia. Revista de Direito Internacional, [s.I.], v. 13, n. 2, p.504-521, 6 nov. 2016. Centro de Ensino Unificado de Brasilia. http://dx.doi.org/10.5102/rdi.v13i2.4169.

SOUZA, Ranidson Gleyck Amâncio. Território das criptomoedas: limites à regulamentação estatal quanto à circulação de moedas no ciberespaço e possíveis alternativas. Revista Brasileira de Políticas Públicas, [s.I.], v. 7, n. 3, p.6178, 6 fev. 2018. Centro de Ensino Unificado de Brasilia. http://dx.doi.org/10.5102/rbpp.v7i3.4902.

STAFFEN, Marcio Ricardo. Superlegality, global law and the transnational corruption combat. Revista Brasileira de Direito, Passo Fundo, v. 14, n. 1, p. 111-130, abr. 2018.

STAFFEN, Márcio Ricardo. Interfaces do direito global. 2. Ed. Rio de Janeiro: Lumen Juris, 2018.

TEUBNER, Gunther. A Bukowina global sobre a emergência de um pluralismo jurídico transnacional. Impulso (Piracicaba), (s.l.), v. 14, n. 33, p.9-31, set. 2003.

TEIXEIRA, Anderson Vichinkeski. Direito público transnacional: por uma compreensão sistêmica das esferas transnacionais de regulação jurídica. Novos Estudos Jurídicos, [s.I.], v. 19, n. 2, p.400-429, 31 jul. 2014. Editora UNIVALI. http://dx.doi.org/10.14210/nej.v19n2.p400-429.

ULRICH, Fernando. Bitcoin: a moeda na era digital. São Paulo: Instituto Ludwig von Mises Brasil, 2014.

VOLPON, Fernanda; RIBEIRO, Marilda Rosado de Sá. Desafios da governança energética global e a participação do BRICS na construção de um novo paradigma energético. Revista de Direito Internacional, [s.I.], v. 15, n. 1, p.199-220, 27 abr. 2018. Centro de Ensino Unificado de Brasilia. http://dx.doi.org/10.5102/rdi.v15i1.5090. 
MANFRON, Bruno Werner; CALETTI, Leandro. Bitcoin: uma análise sobre possibilidades de regulamentação. Revista Eletrônica Direito e Política, Programa de Pós-Graduação Stricto Sensu em Ciência Jurídica da UNIVALI, Itajaí, v.14, n.2, $2^{\circ}$ quadrimestre de 2019. Disponível em: www.univali.br/direitoepolitica - ISSN 1980-7791

ZOLO, Danilo. Globalização: Um mapa dos problemas. Florianópolis: Conceito Editorial, 2010.

RECEBIDO EM: 28/05/2019

APROVADO EM: 23/07/2019 